\title{
First measurement and online monitoring of the stripper foil thinning and pinhole formation to achieve a longer foil lifetime in high-intensity accelerators
}

\author{
P. K. Saha, ${ }^{*}$ M. Yoshimoto, S. Hatakeyama, H. Hotchi, H. Harada®, F. Tamura®, \\ K. Yamamoto, Y. Yamazaki, and M. Kinsho \\ Accelerator division, J-PARC center, Japan Atomic Energy Agency (JAEA), \\ 2-4 Shirakata, Tokai-mura, Naka-gun, Ibaraki 319-1195, Japan \\ Y. Irie $\odot$ \\ High Energy Accelerator Research Organization (KEK), Tsukuba, Ibaraki 305-0801, Japan
}

(Received 22 August 2019; accepted 6 July 2020; published 4 August 2020)

\begin{abstract}
We have established and also implemented a nondestructive online monitoring system for measuring the stripper foil degradation, such as foil thinning and pinhole outbreak, for the first time during beam operation in a high-intensity proton accelerator. We aimed to achieve a realistic and longer lifetime of a stripper foil by ensuring proper uses and determining its end of usefulness without any failure. A stripper foil is used for negative hydrogen $\left(\mathrm{H}^{-}\right)$stripping to proton $(\mathrm{p})$ for multiturn charge-exchange injection in high-intensity proton accelerators. A longer foil lifetime is expected, while foil failure during operation should be avoided, as it reduces the accelerator availability and also has serious issues for regular accelerator maintenance. A proper use of the foil should also be ensured to minimize the replacement of the foil magazine, as it involves unhealthy radiation exposure to the workers. We have measured the partially stripped $\mathrm{H}^{0}$ and unstripped $\mathrm{H}^{-}$charge fractions of the injection $\mathrm{H}^{-}$beam out of the stripper foil to understand details of foil degradation, such as foil thinning and pinhole formation due to high-intensity beam irradiation, which are believed to be foil breaking signals. We used two independent beam monitoring devices and precisely measured both $\mathrm{H}^{0}$ and unstripped $\mathrm{H}^{-}$charge fractions by each monitor. As a result, we obtained a detail of foil degradation during operation to determine a realistic end of its usefulness by successfully achieving a record of nearly $2 \mathrm{yr}$ of operation with a single foil without any failures. The detailed measurement result of the foil degradation also gives strong feedback for producing stronger and durable stripper foils. The present research was done by using simple and ordinary beam diagnostic devices including a nondestructive one, which can be easily applied to overcome the stripper foil issues in any similar existing and next-generation further higher-intensity accelerators.
\end{abstract}

DOI: $10.1103 /$ PhysRevAccelBeams.23.082801

\section{INTRODUCTION}

The multiturn charge-exchange injection (CEI) of negative hydrogen $\left(\mathrm{H}^{-}\right)$is an effective way to increase the proton (p) beam intensity in synchrotrons or storage rings [1-4]. Thin stripper foils usually made of carbon are used to strip two electrons from the $\mathrm{H}^{-}$to inject $\mathrm{p}$ into a circular accelerator. The CEI allows stacking many turns of injection without linear growth in beam emittance because

\footnotetext{
*orresponding author. saha.pranab@j-parc.jp

Published by the American Physical Society under the terms of the Creative Commons Attribution 4.0 International license. Further distribution of this work must maintain attribution to the author(s) and the published article's title, journal citation, and DOI.
}

of injecting in a different charge state, and it provides the opportunity of unlimited multiturn injection until stacking particles exceed the ring acceptance. However, a short lifetime and unexpected failures of stripper foil due to highintensity beam irradiation are serious issues not only to ensure stable and reliable operation of the accelerators, but also for regular maintenance of the accelerator and the foil device as well $[5,6]$. To avoid unexpected failures, a foil is frequently and routinely replaced by a new one, but the foil magazine which contains only a few foils will then run out soon at high-intensity machines. Quantitative foil degradation and a realistic lifetime of the foil are thus never known. In addition, frequent replacement of the foil magazine should be avoided, because the replacement procedure involves unhealthy and high radiation exposure to the worker [7]. As a result, a realistic and longer foil lifetime should be ensured by proper uses to minimize the 
foil changes during operation in order to ensure a foil magazine replacement only during a long accelerator maintenance period. A foil breaking mechanism by measuring quantitative foil degradations during beam irradiation to know a realistic lifetime as well as feedback to the R\&D of durable foil production are essential not only for the existing accelerators running at around $1 \mathrm{MW}$ beam power and considering potential upgrades, but also for nextgeneration multimegawatt proton accelerators [8-10]. Because of high-intensity beam irradiation and the corresponding overheat, foil degradation occurs, which appears as deformation, curling, and wrinkling. An overaccumulation of radiation-induced stress, atomic displacement, and microstructural defects result in a foil rupture. The evolution properties of such molecular and structural changes in a foil strongly depend on temperature rise in a foil, which results in foil thinning and pinhole outbreak before a foil breaks [11]. Numerical estimation of the foil lifetime is difficult as many parameters are involved, which often largely underestimates a lifetime and strongly suggests for measuring foil thinning during beam irradiation [12]. On the other hand, a microstructural change in a foil is also extremely difficult or even impossible to measure during beam irradiation with CEI. A precise measurement of the detailed progression of stripper foil degradation, such as foil thinning and information on the pinhole outbreak during beam irradiation, is thus a superior way for determining a realistic end of usefulness of a foil to ensure proper uses without any failure for achieving a longer foil lifetime and also for strong feedback to the next-generation durable foil production.

The present research has been carried out at the $3-\mathrm{GeV}$ rapid cycling synchrotron (RCS) of Japan Proton Accelerator Research Complex (J-PARC) [1], where the $\mathrm{CEI}$ of $\mathrm{H}^{-}$at $400 \mathrm{MeV}$ energy by using a thin stripper foil has been adopted. Figure 1 shows a schematic view of the RCS. The $\mathrm{H}^{-}$CEI system is located at the first straight section, where the injection $\mathrm{H}^{-}$beam is stripped to $\mathrm{p}$ by using a thin stripper foil and injected in the RCS. The $p$ are accelerated up to $3 \mathrm{GeV}$ before being simultaneously delivered to the Material and Life Science Experimental Facility (MLF) and the main ring (MR) at a repetition rate of $25 \mathrm{~Hz}$. The beam sharing ratio between MLF and MR is 93.5\%:6.5\% or $96.9 \%: 3.1 \%$, depending on the MR operation cycle. The design beam power of the RCS is $1 \mathrm{MW}$ and corresponds to $8.33 \times 10^{13}$ p per pulse, but at present it is $0.5 \mathrm{MW}$ and nearly $0.75 \mathrm{MW}$-equivalent to the MLF and MR, respectively [13].

We have established precise measurement methods and also implemented a nondestructive online monitoring system for stripper foil degradation to ensure proper uses of the foil by determining its realistic end of usefulness as well as to achieve a longer foil lifetime without any failures. Our aim is also to understand a foil breaking mechanism by measuring details of foil degradation, such as foil thinning

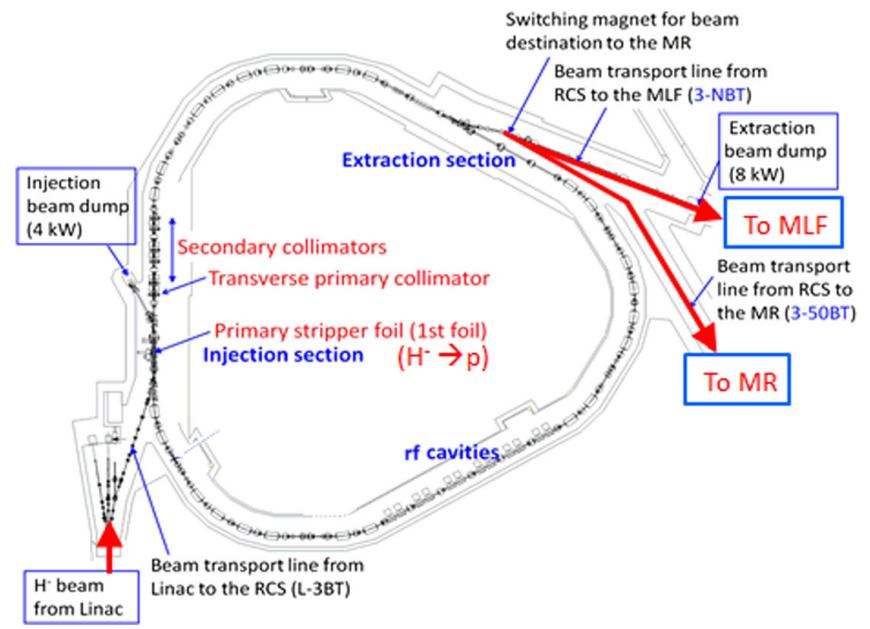

FIG. 1. A schematic view of the 3-GeV RCS at J-PARC. The $400 \mathrm{MeV}$ injection $\mathrm{H}^{-}$beam from the linac is stripped to $\mathrm{p}$ by the primary stripper foil installed at the middle of charge-exchange injection section. The $\mathrm{p}$ are injected into the RCS, accelerated up to $3 \mathrm{GeV}$, and simultaneously delivered to the MLF and MR.

and pinhole outbreak information due to continuous highintensity beam irradiation until a foil reaches its end of life. We used two independent but ordinary beam monitoring devices, and details of their characteristics were reported earlier $[14,15]$. The monitors have been in service for measuring and monitoring stripper foil degradation during RCS operation for more than $10 \mathrm{yr}$, and there has been no record of any foil failure so far. We have achieved a record of nearly $2 \mathrm{yr}$ of operation with a single foil and successfully determined a realistic end of usefulness to replace it with a new one without failure. The present measurement and online monitoring of foil degradation during beam operation itself and, moreover, the understanding of the detailed progression of foil degradation are all conducted for the first time in any accelerators which run with the CEI stripping foil. The detail of foil behaviors achieved in the present research also gives strong feedback for producing stronger stripper foil with less degradation for the near future RCS operation with a beam power of $1 \mathrm{MW}$ and beyond.

\section{THE RCS H' $\mathrm{H}^{-}$CHARGE-EXCHANGE INJECTION SYSTEM AND THE ROLES OF STRIPPER FOILS}

Figure 2 shows a schematic view of the RCS injection system to briefly introduce the CEI method, the stripper foils, and their roles. The CEI at $400 \mathrm{MeV} \mathrm{H}^{-}$beam energy is performed for $0.5 \mathrm{~ms}$ (307 turns) via merging $\mathrm{H}^{-}$and circulating $\mathrm{p}$ beam orbits in the middle of four dipole magnets (SB1-4), where the first stripper foil is installed. The thickness of the first foil is $333 \mu \mathrm{g} / \mathrm{cm}^{2}$ to strip $99.7 \%$ of $\mathrm{H}^{-}$to $\mathrm{p}$ by removing its both electrons. The $\mathrm{p}$ are injected into the RCS and accelerated up to $3 \mathrm{GeV}$. The remaining $0.3 \%$ of the $\mathrm{H}^{-}$are mainly the partially 


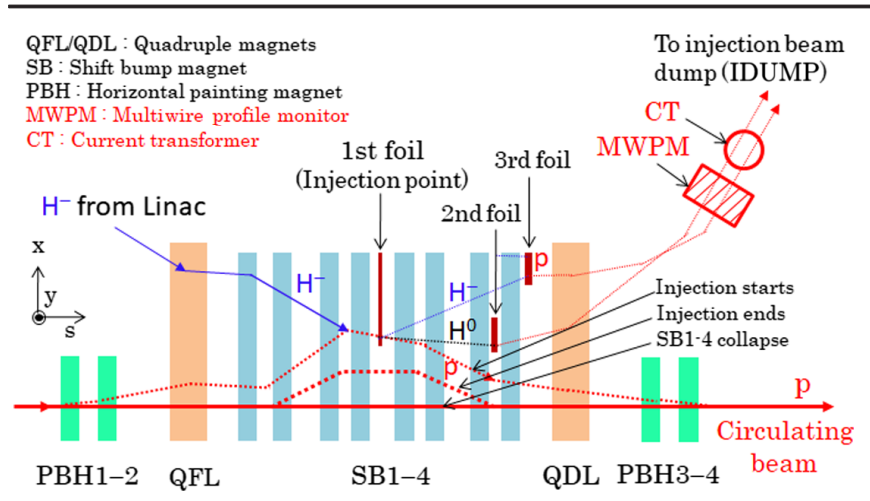

FIG. 2. A schematic view of the RCS injection area, location of stripper foils, and their roles. $99.7 \%$ of the $\mathrm{H}^{-}$is stripped to $\mathrm{p}$ by the first foil and injected into the RCS. The partially stripped $\mathrm{H}^{0}$ and unstripped $\mathrm{H}^{-}$are further stripped to $\mathrm{p}$ by the second and third foils, respectively, and directed to the IDUMP.

(single electron) stripped by the first foil. They are called neutral hydrogen $\mathrm{H}^{0}$, while the unstripped $\mathrm{H}^{-}$are ideally negligibly small $\left(1.995 \times 10^{-5} \%\right)$ [15]. The $\mathrm{H}^{0}$ and unstripped $\mathrm{H}^{-}$are called waste beams. Those are further stripped to $\mathrm{p}$ by two thicker $\left(500 \mu \mathrm{g} / \mathrm{cm}^{2}\right)$ downstream foils, named second and third foils, respectively, and directed to the injection beam dump (IDUMP).

The role of the first stripper foil is very significant, as it takes all the injection $\mathrm{H}^{-}$beam, while each circulating $\mathrm{p}$ also hits the foil many times during multiturn injection. Figure 3 shows simulated circulating beam distributions on the first foil for the MLF (black) and MR (red) at the end of injection. The foil sizes in the horizontal and vertical directions are typically 110 and $20 \mathrm{~mm}$, respectively. To reduce circulating $\mathrm{p}$ hitting on the first foil, the injection $\mathrm{H}^{-}$is placed as close as possible to the edge of the foil. The $\mathrm{H}^{-}$beam center is set at $9 \mathrm{~mm}$ from the foil edge in the horizontal direction, while it is at the center in the vertical direction. In addition, transverse painting (TP) at injection is also performed by sweeping the circulating beam away from the foil $[16,17]$. As a result, the circulating beam goes through large betatron oscillations to reduce the foil hit significantly. However, due to a relatively smaller TP area for the MR, the sweeping rate is slower, and, thus, the circulating $\mathrm{p}$ slowly moves away from the foil as compared to a large TP area for the MLF. The average foil hits of each injected beam is nearly one order of magnitude higher of 65 for the MR pulses as compared to only 7 for the MLF ones. However, RCS duty for the MR is only $6.5 \%$ at best, and the average foil traversal is then estimated to be about 11 . The cumulative charge via the first foil for 1 day operation at the designed $1 \mathrm{MW}$ beam power is estimated to be $317 \mathrm{C}$, which is only less than $0.1 \mathrm{C}$ in total for both secondary foils.

Figure 4 shows the power distributions in the foil estimated from simulated particle hit distributions for the MLF (top) and MR (bottom) with $4.2 \times 10^{13}$ and $6.25 \times 10^{13}$ particles per pulse (ppp), respectively, as in the present operation. The ppp for the MR is only 1.5 times

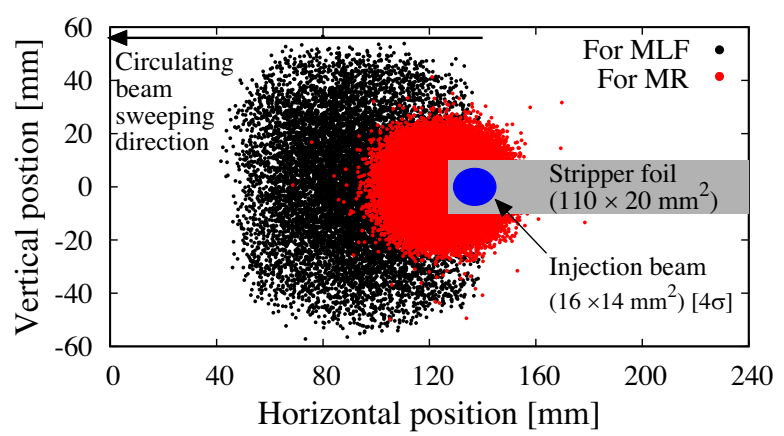

FIG. 3. Simulated circulating p distributions on the first foil at the end of injection for the MLF (black) and MR (red) beam parameters. Because of a smaller TP area for the MR, the sweeping rate of circulating $\mathrm{p}$ is slower, which results in an order of magnitude higher average foil traversal of each injected $p$ as compared that of MLF with a bigger TP area.

higher than MLF, but, due to an order of magnitude higher average foil traversal of each injected $\mathrm{p}$, the corresponding power distribution rate is also accordingly higher for the MR pulses as compared to the MLF pulses. The foil peak temperature is thus dominated by the MR pulses.

To achieve durable foil lifetime, a new type of stripper foil named hybrid-type boron-doped carbon (HBC) foil, which was developed at KEK, is used in the RCS [18]. The foil is produced by an arc evaporation process, called the controlled dc arc-discharge method. The cathode and the anode are boron-doped carbide $\left(\mathrm{B}_{4} \mathrm{C}\right)$ and pure graphite rods, respectively. The HBC foil typically with a carbon and boron ratio of $80: 20$ is used for the RCS operation. To reduce the pinholes, two foils of half thickness than the required one are sandwiched together and supported by $\mathrm{SiC}$ (silicon carbide) fibers of $7 \mu \mathrm{m}$ diameter. The HBC foil is believed to have high robustness to withstand highintensity beam irradiation. The foil lifetime might depend

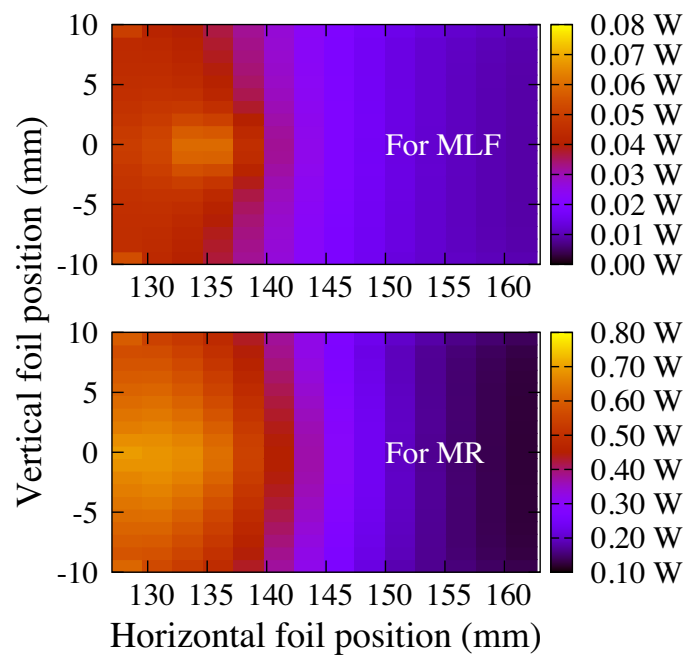

FIG. 4. Power deposition distributions in the foil estimated from the simulated particle hit distributions for the MLF (top) and MR (bottom) pulses. 
on initial crystal lattice structure, and their destruction with beam irradiation is believed to be strong in the HBC foils. Nevertheless, the foil degradation and the lifetime are reported to vary significantly depending on the foil types and their thickness as well [11]. However, not only were those measurements done with completely different conditions than realistic CEI in high-intensity accelerators, but also the experimental durability was short and was not online. An online measurement of the foil degradation and detailed progression of the foil degradation process during beam operation are thus highly essential.

\section{BRIEF INTRODUCTION OF THE PRESENT MONITORS}

In order to obtain detailed degradation of the first stripper foil, we measured both partially stripped $\mathrm{H}^{0}$ and unstripped $\mathrm{H}^{-}$waste beam charge fractions by using two independent monitors, namely, a current transformer (CT) and a multiwire profile monitor (MWPM) placed near the IDUMP as shown in Fig. 2. The CT is also used for online monitoring of the foil degradation. As both partially stripped $\mathrm{H}^{0}$ and unstripped $\mathrm{H}^{-}$fractions are ideally very small and practically hard to measure in an ordinary way, we utilized a fast Fourier transformation (FFT) analysis of the raw signal taken by the CT to identify even a small fraction of the beam corresponding to the chopping frequency of the injection $\mathrm{H}^{-}$beam, while the integrated beam profile yields measured by the MWPM were used for that purpose.

Figure 5 shows a schematic drawing of the CT configuration for its general purpose and also the data taking logic for the present purpose. The CT is originally used for the personal protection system (PPS) interlock system with two-stage amplifications of the original signal. More details on the CT can be found in our earlier article [14]. For our present purpose, we fed the amplified and buffered signal into an oscilloscope, which is controlled by an operation interface (OPI). The main parameters of the oscilloscope are controlled online by the OPI. The time domain data for many shots are averaged before the FFT analysis is applied to sufficiently to minimize the random noises. Usually, an

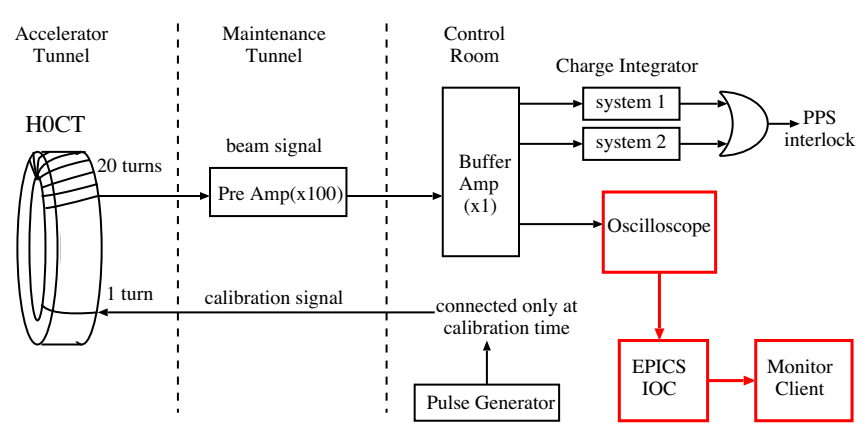

FIG. 5. A schematic drawing of the CT configuration and data taking logic. A two-stage amplified buffered signal was fed to an oscilloscope and controlled through an OPI. average of 1024 injections is done, which takes $41 \mathrm{~s}$ for one data point as the RCS repetition rate is $25 \mathrm{~Hz}$. The linearity of the CT was measured and found to be good [14].

Figure 6 shows the geometrical parameters and the drawing of the MWPM wire configuration, which is installed in a rectangular Ti chamber for low activation [19]. Relatively thicker Ti wires of $1 \mathrm{~mm}$ width and $10 \mu \mathrm{m}$ thickness are used to increase the secondary electron emission yields induced from the proton beam intercepted by the wires. There are 15 wires with $20 \mathrm{~mm}$ pitch and 48 wires with $4.3 \mathrm{~mm}$ pitch tilted at $17.7^{\circ}$ in the $\mathrm{u}$ and v planes, respectively. The beam profiles in the $\mathrm{u}$ and $\mathrm{v}$ planes can be thus simultaneously measured. The MWPM is scanned in the horizontal direction for 100 shots at $0.2 \mathrm{~mm}$ step for a total of $20 \mathrm{~mm}$ scan through the beam. The beam-induced charge signals are transported by using shielded twisted pair cables for amplification by using a preamplifier located in the basement subtunnel around $40 \mathrm{~m}$ far from the wire sensor. The amplified signals are transferred to the charge integrators for integrating a $500 \mu$ s period starting at the end of beam injection (macropulse) and sequentially multiplexed (MPX) with $10 \mu$ s intervals. The MPX output signals are transferred to a digitizer called the wave endless recorder located at the ground floor and recorded as waveform data. The waveform data are imported by an application software program to reconstruct the beam profile in the $u$ and $v$ planes, which are then transformed to the horizontal and vertical directions by using matrix transformation taking into account the wire inclination [20,21].

The horizontal beam profiles of the unstripped $\mathrm{H}^{-}$and the partially stripped $\mathrm{H}^{0}$ at the MWPM are separated by about $80 \mathrm{~mm}$ from each other. The $\mathrm{H}^{-}$and $\mathrm{H}^{0}$ yields are obtained by integrating each horizontal beam profile. For each setting, data are usually taken three times, from which the statistical mean value and the errors are obtained for further analysis. Background data with no beam trigger are also taken and subtracted from the data taken with the beam

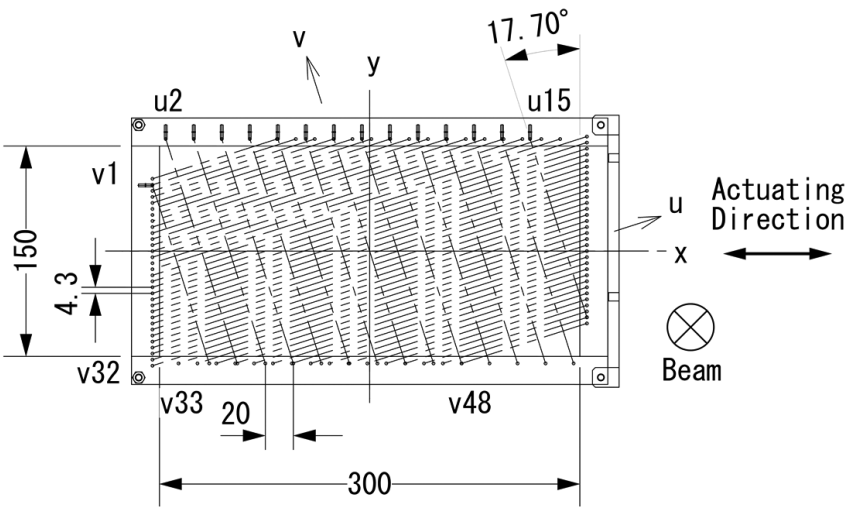

FIG. 6. The geometrical parameters and the drawing of the MWPM wire configuration at the $\mathrm{u}$ and $\mathrm{v}$ planes for simultaneously measuring the horizontal and vertical beam profiles, respectively. 
to eliminate the noise in the beam profile. The linearity of the MWPM was also extensively studied and was found to be good [15]. However, due to a comparatively lower beam intensity used to avoid any breaking of the MWPM wires because of overheating, the statistical measurement error of the MWPM is larger than that of CT measurements.

\section{MEASUREMENT PRINCIPLE}

In order to quantitatively and precisely measure foil degradation during beam operation, we have established new techniques by using ordinary beam monitoring devices. Our new technique is to measure both partially stripped $\mathrm{H}^{0}$ and the unstripped $\mathrm{H}^{-}$beams at the beam transport of injection beam dump (IDUMP). Once the $\mathrm{H}^{0}$ and $\mathrm{H}^{-}$ fractions are known, the $\mathrm{p}$ fraction injected into the RCS can be automatically calculated. The stripping efficiency and the foil thickness can be then estimated by using the measured cross sections [15].

Figure 7 shows the measurement procedure used in the present study. The unstripped $\mathrm{H}^{-}$and the partially stripped $\mathrm{H}^{0}$ waste beam yields together are measured online by the
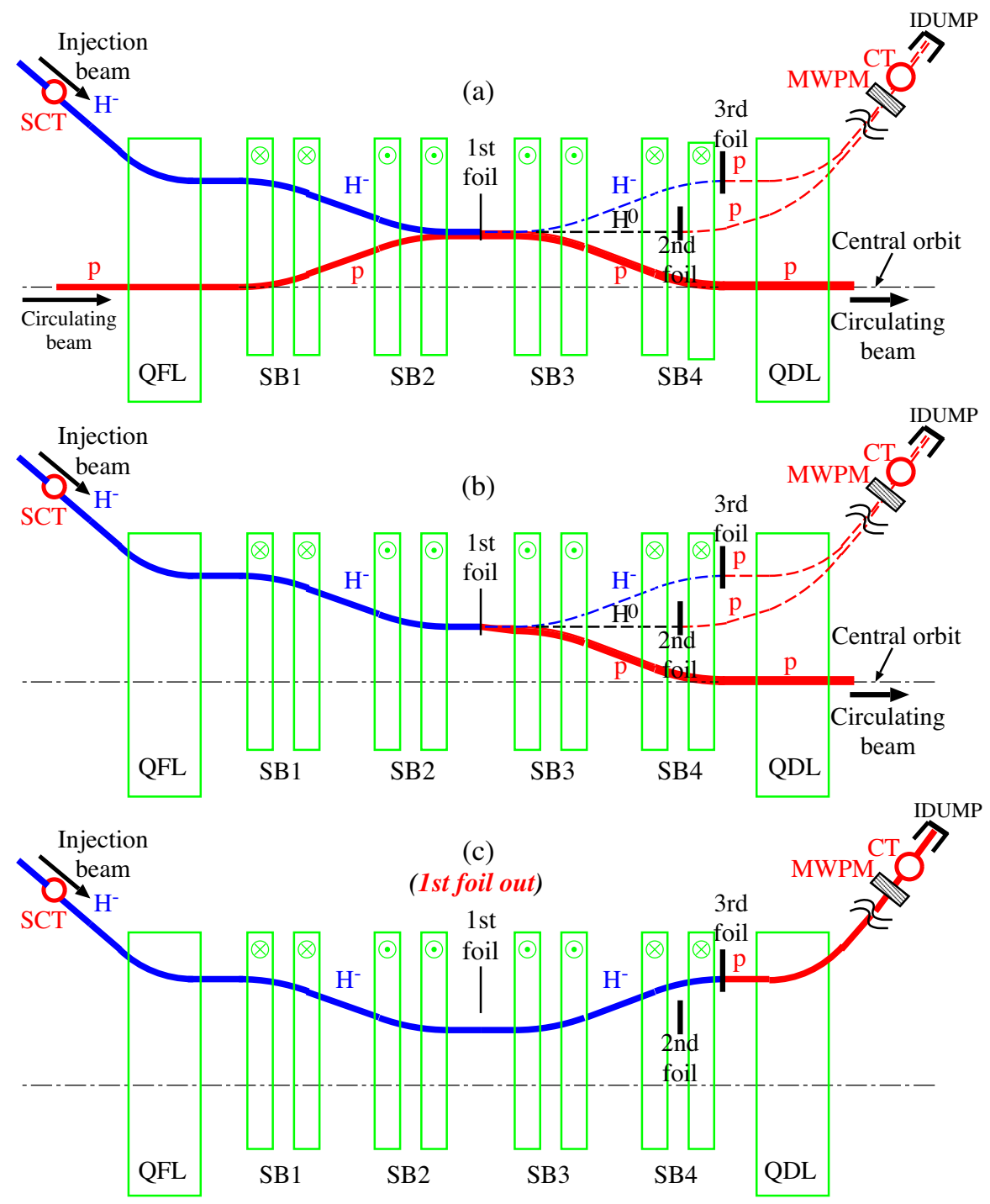

FIG. 7. RCS operation modes used in the present study for quantitative measurement of stripper foil degradation. In the circulating mode (a), the waste beams in total are measured online by the CT during RCS operation. For detailed studies of stripper foil degradation, the $\mathrm{H}^{-}$and $\mathrm{H}^{0}$ yields are separately and independently measured by both CT and the MWPM in the single-pass extraction mode (b). The $\mathrm{H}^{-}$and $\mathrm{H}^{0}$ beam profiles are simultaneously measured by the MWPM as they are separated by about $80 \mathrm{~mm}$ from each other. However, the measurement by the CT needs two steps. First, the $\mathrm{H}^{-}$and $\mathrm{H}^{0}$ are measured together, and then the third foil is removed to measure only the $\mathrm{H}^{0}$ yield, from which the $\mathrm{H}^{-}$yield is obtained. The $\mathrm{H}^{-}$and the $\mathrm{H}^{0}$ yields measured in mode $\mathrm{b}$ are divided by the injection beam yield measured in the injection beam dump mode (c) to obtain each charge fraction. Similarly, the total charge fraction during beam operation mode a is also obtained. The injection beam upstream of the first foil is also always taken together by using an SCT to take into any fluctuation of the injection beam. 
CT during RCS operation in the upper mode (a) called the circulating mode. To obtain any change of the foil thickness and pinhole outbreak information, detailed measurements are done at scheduled accelerator tuning and beam physics study days. In this case, the $\mathrm{H}^{-}$and $\mathrm{H}^{0}$ yields are separately and independently measured by both CT and the MWPM in the single-pass extraction mode (b). In this mode, the injected $\mathrm{p}$ are transported to an extraction beam dump after circulating only one-third of the RCS circumference. The $\mathrm{H}^{-}$and $\mathrm{H}^{0}$ yields are simultaneously obtained by measuring both beam profiles as they are separated by $80 \mathrm{~mm}$ from each other with no overlaps. This is for the CT obtained as follows. After measuring $\mathrm{H}^{-}$and $\mathrm{H}^{0}$ yields together, the third foil is removed to measure only the $\mathrm{H}^{0}$. In this case, any unstripped $\mathrm{H}^{-}$is not stripped to $\mathrm{p}$ by the third foil and deflected to the opposite direction by the defocusing quadruple magnet (QDL) and lost a few meters downstream of the QDL. A subtraction of the $\mathrm{H}^{0}$ yield from the $\mathrm{H}^{-}$and $\mathrm{H}^{0}$ yields measured together gives only the $\mathrm{H}^{-}$ yield. Finally, the injection $\mathrm{H}^{-}$beam yield itself is also separately measured by both MWPM and the CT in the injection beam dump mode (c). In this mode, the first foil removed from the beam line and, thus, all $\mathrm{H}^{-}$are stripped to $\mathrm{p}$ by the third foil and transported to the IDUMP. As in this case all injection $\mathrm{H}^{-}$are transported to the IDUMP, the beam intensity for the MWPM measurement is reduced to nearly $1 / 100$ (by reducing the number of intermediate pulses) to avoid any breaking of the MWPM wires. The $\mathrm{H}^{-}$and $\mathrm{H}^{0}$ yields measured in mode $\mathrm{b}$ are divided by the injection beam yield to obtain the charge fractions. The charge fractions are thus separately obtained by the MWPM and CT measurements. In a similar way, the total charge fraction $\left(\mathrm{H}^{-}\right.$and $\mathrm{H}^{0}$ together) during beam operation mode (a) is also obtained by the CT. For any measurements, the injection beam current upstream of the first foil is also always taken by using a slow current transformer (SCT) together with the present $\mathrm{CT}$ to take into account any fluctuation and/or change of the injection beam current.

However, one of the biggest difficulties is that one has to measure only small fractions of the waste beams at the IDUMP by overcoming huge noises from many types of devices at the injection area. Our technique to completely overcome such a difficulty is as follows: The injection $\mathrm{H}^{-}$ macropulse from the linac is chopped, matching with the RCS revolution frequency (harmonic number $h=2$ ) to capture into two rf buckets in the RCS. The chopped injected pulses are called intermediate pulses, which have a frequency of $1.2285 \mathrm{MHz}$. Figure 8 shows a schematic view of the micropulse structure (top) of the $\mathrm{H}^{-}$beam and their intermediate pulse structure (bottom) matched with the RCS rf period for injection into the RCS. The frequency of the intermediate pulse is $1.2285 \mathrm{MHz}$. To measure the partially stripped $\mathrm{H}^{0}$ and the unstripped $\mathrm{H}^{-}$beams by the CT, we applied an FFT analysis on the time domain data to

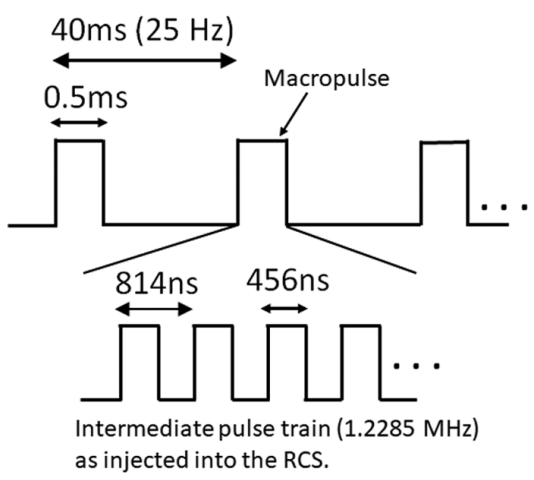

FIG. 8. Schematic view of the $\mathrm{H}^{-}$intermediate pulse structure in each $0.5 \mathrm{~ms}$ injection macropulse as injected into the RCS. The intermediate pulses have a frequency of $1.2285 \mathrm{MHz}$.

obtain a signal corresponding to the known frequency of the intermediate pulses.

Figure 9 shows the time domain signal of the waste beam (unstripped $\mathrm{H}^{-}$and partially stripped $\mathrm{H}^{0}$ ) taken in the single-pass extraction mode by the CT at the IDUMP for a typical injection period of $0.3 \mathrm{~ms}$ at present. The data with a beam and without a beam (background) shown by the red and black are very identical, and it is very hard to extract the real information. However, an FFT analysis of the time domain data with a beam gives clear signals corresponding to the chopping frequency of $1.2285 \mathrm{MHz}$ and rf higher multiples as shown in Fig. 10. There is no such signal for the data without a beam. An expanded view of the FFT spectra near the fundamental frequency region is also shown in the inset.

The data shown in Figs. 9 and 10 were taken for the first beam irradiation on the present $\mathrm{HBC}$ foil used for a longer beam operation. For the analysis, we have subtracted the time domain no beam data from that with beam data before applying the FFT. The FFT amplitude corresponding to the fundamental frequency was used for the analysis. The waste beam yield in this case included both $\mathrm{H}^{-}$and $\mathrm{H}^{0}$ components, and to get them separately the $\mathrm{H}^{0}$ fraction itself was measured by removing the third foil. The $\mathrm{H}^{-}$ yield was obtained by subtracting the $\mathrm{H}^{0}$ yield from the total yield $\left(\mathrm{H}^{-}\right.$and $\left.\mathrm{H}^{0}\right)$. The unstripped $\mathrm{H}^{-}$and the partially stripped $\mathrm{H}^{0}$ charge fractions were obtained by dividing each FFT amplitude by that of total injection $\mathrm{H}^{-}$measured in the injection beam dump mode. The above detailed measurements by using the CT were usually done on the scheduled accelerator tuning and beam physics study days, while the CT was always used for measuring the $\mathrm{H}^{-}$and the $\mathrm{H}^{0}$ charge fractions together online in the beam operation mode called the circulating mode.

The unstripped $\mathrm{H}^{-}$and partially stripped $\mathrm{H}^{0}$ fractions at the first beam irradiation of the present $\mathrm{HBC}$ foil were obtained to be $(0.0263 \pm 0.0013) \%$ and $(0.3240 \pm$ $0.008) \%$, respectively. The $\mathrm{p}$ fraction injected into the RCS was calculated to be $(99.676 \pm 0.0093) \%$. The foil 


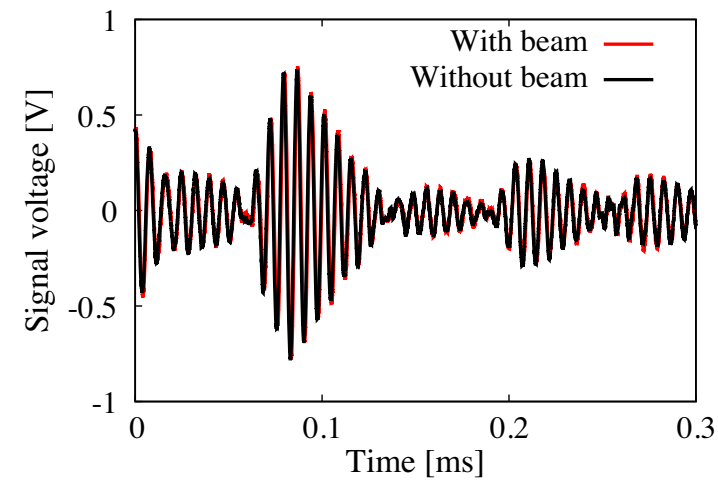

FIG. 9. Time domain signals of the CT with a waste beam (red line) and with no beam (black line). The signals are almost identical, and it is extremely difficult to get a real beam signal.

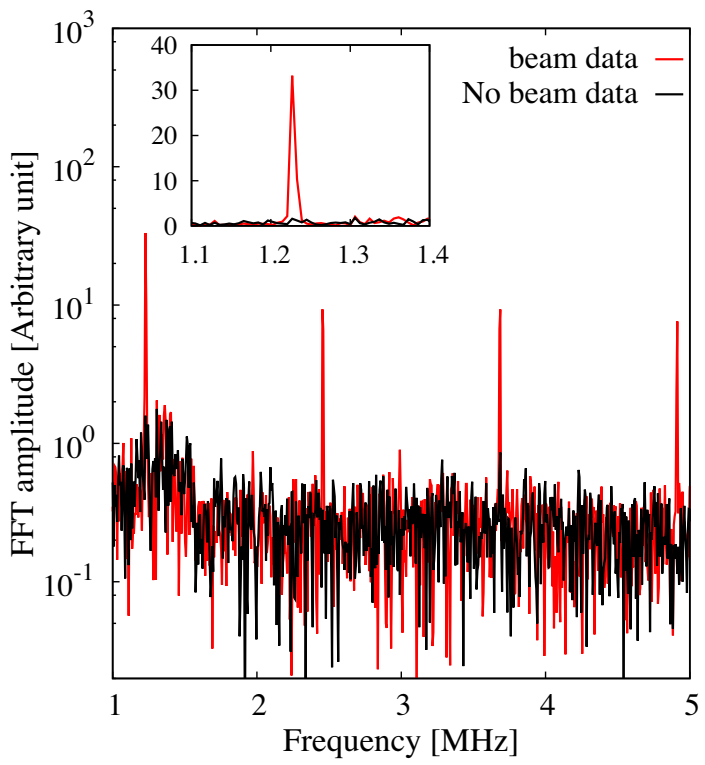

FIG. 10. FFT of the time domain data with the waste beam and no beam. The FFT amplitude corresponding to the chopping frequency and higher rf multiples clearly shows the signal of the waste beam. An expanded view of the FFT spectra near the fundamental frequency region is shown in the inset.

thickness based on the $\mathrm{H}^{0}$ charge fraction was calculated to be $329.1 \pm 1.6 \mu \mathrm{g} / \mathrm{cm}^{2}$, which was very close to the designed and expected thickness of $333 \mu \mathrm{g} / \mathrm{cm}^{2}$.

The measurement errors were obtained by the fluctuation of the FFT amplitude from the data taken several times for each setting. The fluctuation of the injection beam measured by an SCT upstream of the foil (see Fig. 7) was also taken into account in the analysis. However, the fluctuation of the injection beam was as small as $0.1 \%$ and was estimated to have no significant effect for the measured charge fractions and the corresponding foil thickness. The effect of the supporting $\mathrm{SiC}$ fibers used for the foil mounting, which could be a systematic error, was also experimentally determined. A frame of only $\mathrm{SiC}$ fibers with the same wire configuration as used for a foil mounting was installed. A difference of injection $\mathrm{H}^{-}$yields at the IDUMP in the injection beam dump mode was measured with and without the $\mathrm{SiC}$ fiber frame. The injection $\mathrm{H}^{-}$stripped by the supporting $\mathrm{SiC}$ fibers used for mounting the first stripper foil was measured to be $1 \%$, and the corresponding foil thickness error was estimated to be only $0.5 \mu \mathrm{g} / \mathrm{cm}^{2}$. We have also checked the stripping efficiencies of the second and third foils from time to time by scanning their positions for $\pm 15 \mathrm{~mm}$ from their usual positions. In this case, the stripping efficiency of $\mathrm{H}^{0}$ and $\mathrm{H}^{-}$by the second and third foil, respectively, was measured. It is worth mentioning that the injection beam position on the first foil is usually adjusted within $\pm 0.1 \mathrm{~mm}$ as compared to the designed position. The beam positions on the secondary foils are thus adjusted almost within similar values. The position dependence stripping efficiencies of the second and third foils at the lowest during the present study were measured to be $99.95 \%$ and $99.97 \%$, respectively. The position dependence efficiencies of the secondary foils on the measured charge fractions and the corresponding foil thickness were also thus estimated to be negligibly small.

In addition to the CT, we also performed the same measurement by using the MWPM. The MWPM can simultaneously measure both $\mathrm{H}^{-}$and $\mathrm{H}^{0}$ waste beam profiles, as they are nearly $80 \mathrm{~mm}$ separated from each other in the horizontal direction. Figure 11 shows the horizontal waste beam profiles measured by the MWPM in the single-pass extraction mode for the present HBC foil at the first beam irradiation. The horizontal and vertical axes are the wire position and the signal in volts $(\mathrm{V})$, respectively. Similar to the $\mathrm{CT}$, the injection $\mathrm{H}^{-}$yield itself was also measured in the injection beam dump mode. However, unlike the CT, only a few intermediate pulses were chosen in this case to avoid any breaking of the MWPM wires.

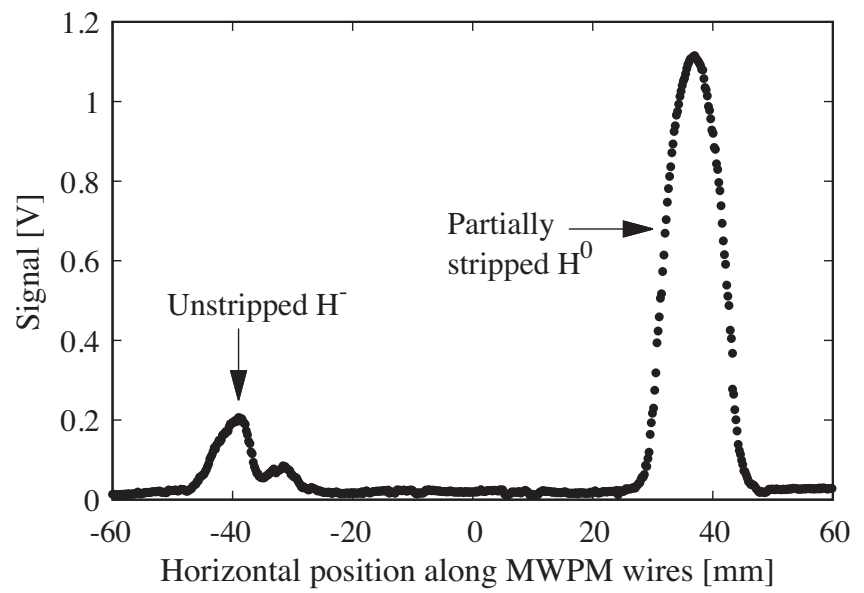

FIG. 11. Horizontal beam profiles of the unstripped $\mathrm{H}^{-}$and partially stripped $\mathrm{H}^{0}$ waste beams measured by the MWPM at the first beam irradiation on the present $\mathrm{HBC}$ foil. 
The unstripped $\mathrm{H}^{-}$and the partially stripped $\mathrm{H}^{0}$ yields measured in the single-pass extraction mode are normalized by the injection $\mathrm{H}^{-}$yield and the number of intermediate pulses measured in the injection beam dump mode to obtain the $\mathrm{H}^{-}$and $\mathrm{H}^{0}$ charge fractions.

The unstripped $\mathrm{H}^{-}$and the partially stripped $\mathrm{H}^{0}$ fractions from the MWPM data were obtained to be $(0.0342 \pm$ $0.009) \%$ and $(0.3294 \pm 0.028) \%$, respectively. The $\mathrm{p}$ fraction injected into the RCS was then calculated to be $(99.6706 \pm 0.037) \%$. The foil thickness was estimated to be $328.1 \pm 5.2 \mu \mathrm{g} / \mathrm{cm}^{2}$, which was consistent with the CT result. However, as MWPM intercepts the beam and is not a nondestructive-type device, it is used only for detail measurement on the scheduled accelerator tuning and beam physics study days.

\section{ONLINE MONITORING AND MEASUREMENT RESULTS OF FOIL THINNING AND PINHOLE FORMATION DURING OPERATION}

In this section, online measurement results of foil degradation by using the $\mathrm{CT}$ and the detailed measurement results by using both CT and the MWPM on the scheduled accelerator beam tuning and beam physics study days are given first. The foil thinning and pinhole information estimated from the detailed measurements are given in the later part of this section.

Figure 12 (top) shows the total $\left(\mathrm{H}^{-}\right.$and $\left.\mathrm{H}^{0}\right)$ waste beam fraction (gray) measured online by the $\mathrm{CT}$ as a function of the date. The individual and detail measurements results obtained by the MWPM and CT are also given together as shown by the blue and red solid circles, respectively. The measurement errors of the CT are comparatively smaller than MWPM measurements and are within the size of the symbols. The cumulative charge via the foil by taking into account an average foil hit of 11 for each injected particle is also shown by the black solid line with respect to the right vertical axis, which reached as high as more than $35000 \mathrm{C}$ at the end. If calculated for the designed $1 \mathrm{MW}$ operation $\left(8.33 \times 10^{13}\right.$ proton per pulse), the present total charge via foil corresponds to nearly $20 \mathrm{wk}$ operation by considering scheduled maintenance time (11\%) and typical downtime of the accelerators (10\%), and it is one order higher than estimated only 2 wk per foil at the design stage. However, it can be noticed that the degradation at the later cycles with higher beam intensity, especially due to operation with $1 \mathrm{MW}$ beam power for about an $1 \mathrm{~h}$, was very fast and significant. It is worth mentioning that any fluctuation or change of the injection beam current was taken into consideration in the analysis, measuring it always by using an SCT upstream of the injection point (see Fig. 7). The transverse and longitudinal injection beam parameters including injection beam orbit at the beam transport and the beam position at the first foil were also routinely checked and adjusted if needed almost every week after the accelerator maintenance work.

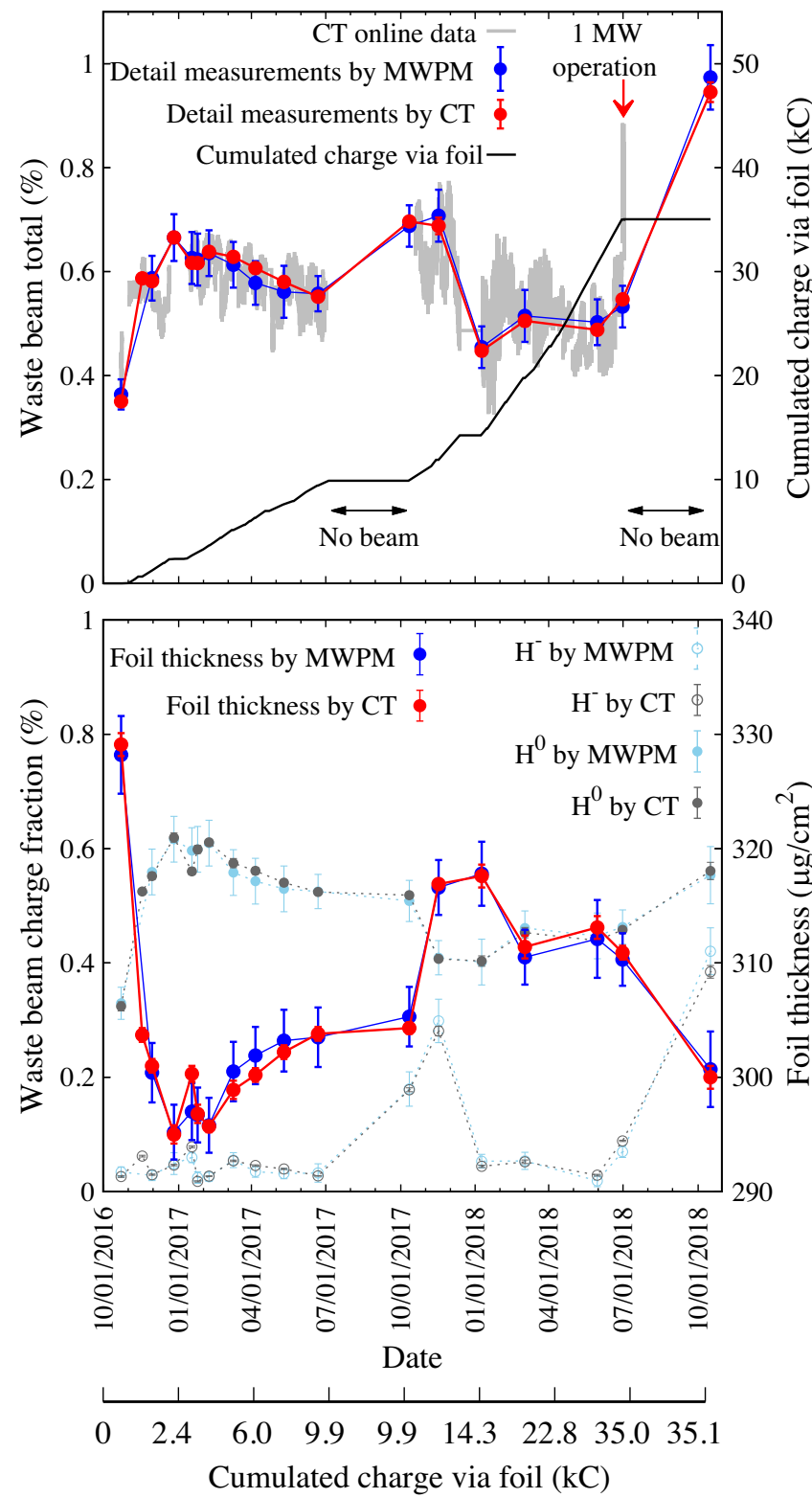

FIG. 12. (Top) Online measurement results of the total waste beam fraction obtained by the CT during RCS operation for nearly 2 yr. The individual measurement results obtained by using both CT and the MWPM are also plotted together. The cumulative charge via the foil is shown by the black curve plotted with respect to the right vertical axis. The charge fractions and the corresponding estimated effective foil thickness obtained from the detail measurements are shown in the figure at the bottom.

Figure 13 shows photographs of the foil taken during beam irradiation until it reached its end of life. A progression of physical deformation, such as curling and wrinkling due to accumulated beam irradiation stress, shows a qualitative degradation of the foil. However, it is difficult to determine the foil lifetime by looking at only physical deformation, as the foil looked widely deformed even at early stages. Because of cumulative charge via the foil and fast beam intensity ramp up at later cycles, the foil 


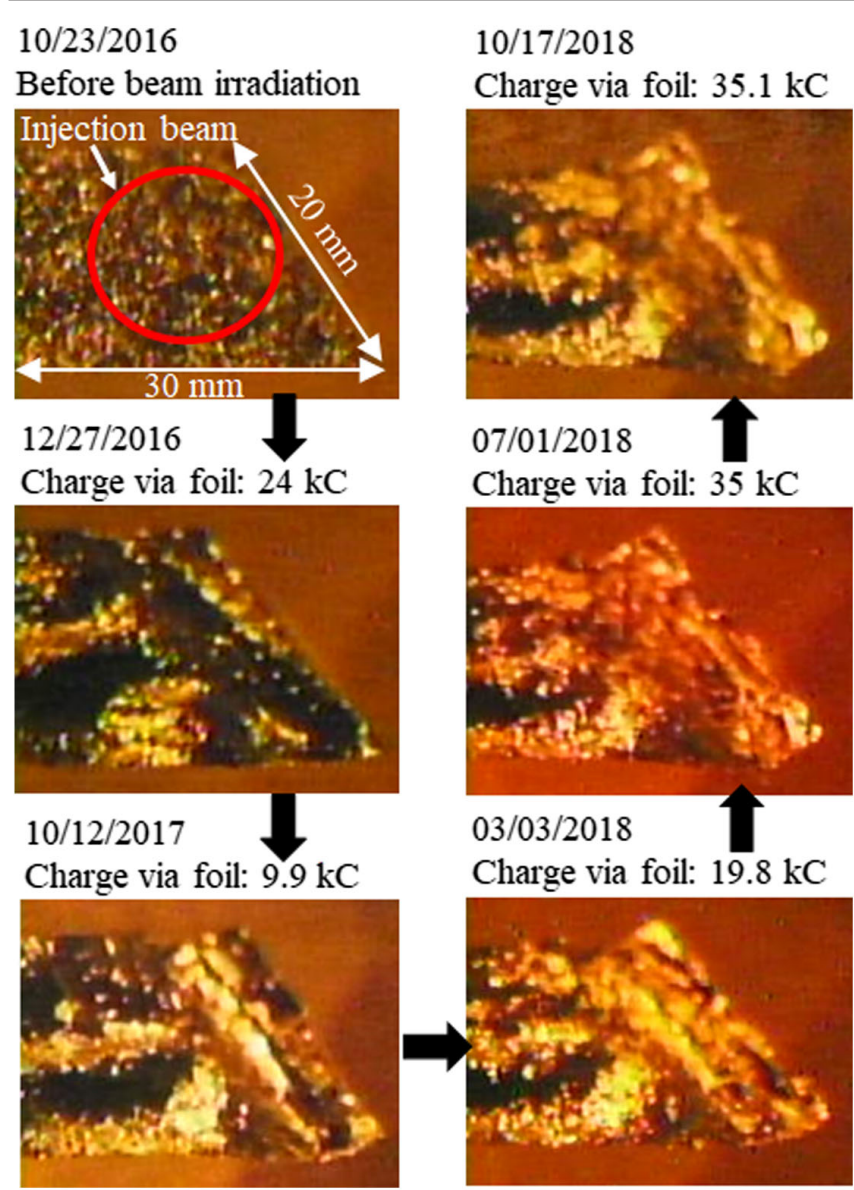

FIG. 13. Photographs of the stripper foil taken during beam irradiation. A qualitative progression of the foil degradation was observed as accumulated charge was increased. The foil started to deform around the injection beam center first, then the curling was quite visible after one year operation, and it grew faster at the end of $2 \mathrm{yr}$ operation.

temperature increased and the degradation also grew faster, especially during $1 \mathrm{MW}$ beam power operation. The waste beam reached the highest as measured to be nearly $1 \%$ at the end of $1 \mathrm{MW}$ operation. Although the foil visually looked almost not changed before and after $1 \mathrm{MW}$ operation, such a rapid degradation includes both foil thinning and pinhole outbreaking, which might be the foil breaking signal [11]. Since no beam was available after $1 \mathrm{MW}$ operation due to accelerator maintenance, the detail measurements of this foil were done 3 months later in October, 2018. The waste beam fraction measured by the CT and MWPM was $(0.950 \pm 0.020) \%$ and $(0.974 \pm 0.063) \%$, respectively, which were nearly 3 times higher than expected in an ideal case.

The detailed measurement results of the foil degradation obtained by both monitors are shown at the bottom in Fig. 12. The partially stripped $\mathrm{H}^{0}$ and the unstripped $\mathrm{H}^{-}$ fractions are plotted by the solid and empty circles, respectively, while the gray colors are MWPM measurements and light-blue colors are the CT measurements. As the cross section of unstripped $\mathrm{H}^{-}$fraction is negligibly small $\left(\sim 10^{-5} \%\right.$ for a foil of $\left.\sim 300 \mu \mathrm{g} / \mathrm{cm}^{2}\right)$, the foil thickness mainly depends on the $\mathrm{H}^{0}$ fraction. The effective foil thicknesses estimated for each measurement are plotted with respect to the vertical axis in the right. The foil thickness significantly decreases at the beginning, but, as deformation continues such as a wrinkle or curling, the thickness slightly increases and remains almost stable until again a rapid thinning occurs due to the beam power ramp up at later cycles, especially during $1 \mathrm{MW}$ operation. At this stage, not only a foil thinning but also a significant increase of the unstripped $\mathrm{H}^{-}$is also highly noticeable. The $\mathrm{H}^{0}$ fraction measured by the CT and MWPM was $(0.5609 \pm$ $0.015) \%$ and $(0.5535 \pm 0.05) \%$, respectively, which was nearly 2 times higher than the initial value. The effective foil thickness was measured to be reduced to $300 \mu \mathrm{g} / \mathrm{cm}^{2}$ from its initial thickness of $330 \mu \mathrm{g} / \mathrm{cm}^{2}$. Moreover, the unstripped $\mathrm{H}^{-}$was as high as $(0.3844 \pm 0.015) \%$ and $(0.4203 \pm 0.031) \%$ as measured by the CT and MWPM, respectively, which was 16 times higher than its initial value and 4 orders of magnitude than the ideal value of $\sim 10^{-5} \%$. It is worth mentioning that the excessive $\mathrm{H}^{-}$ measured around the middle period were due to insufficient tuning of the injection beam, which is more understandable by the MWPM data as presented below.

Figure 14 shows the vertical profiles of the unstripped $\mathrm{H}^{-}$and partially stripped $\mathrm{H}^{0}$ charge fractions of the waste beams measured by the MWPM for some particular dates including the initial and final ones. A change of the effective foil thickness as was shown at the bottom in Fig. 12 clearly corresponds to a change of the $\mathrm{H}^{0}$ fraction,

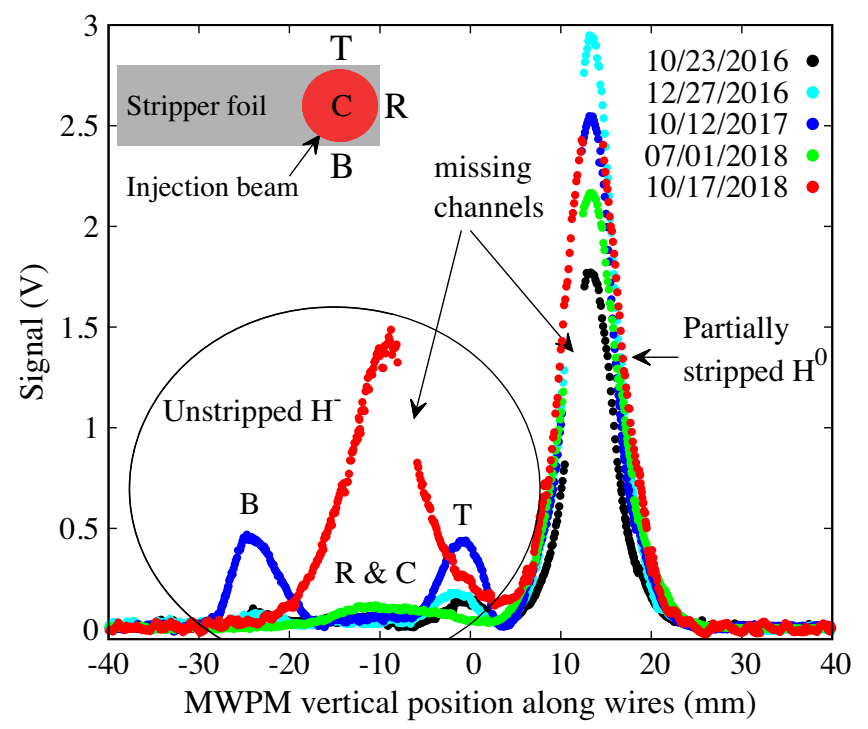

FIG. 14. The vertical profiles of the partially stripped $\mathrm{H}^{0}$ and unstripped $\mathrm{H}^{-}$beam measured by the MWPM. It can be seen that the $\mathrm{H}^{0}$ yield increased due to foil thinning, while the missing $\mathrm{H}^{-}$ were also significantly increased due to a pinhole outbreak in the foil and its curling edges. 
while an increase of the $\mathrm{H}^{-}$fraction due to a pinhole outbreak in the foil and its deformation and curling can also be seen. The excessive $\mathrm{H}^{-}$in the middle period (end of 2017 to beginning of 2018) as shown in the bottom in Fig. 12 was due to insufficient tuning of the $\mathrm{H}^{-}$injection beam in the linac. The transverse beam profile, especially the vertical one, was much broader with higher beam halos than expected, causing the $\mathrm{H}^{-}$beam missing from the bottom (B) and top (T) at the foil can be clearly seen by the profile measured December 10, 2017 (blue). The transverse beam profile monitors used for $\mathrm{H}^{-}$beam matching at the last section of linac were broken. The beam matching at the downstream beam transport including the RCS injection point thus could not be tuned well. As a result, a significant amount of $\mathrm{H}^{-}$missed the foil vertically, causing an increase of the unstripped $\mathrm{H}^{-}$waste beam fraction at the IDUMP. The monitors were later fixed, and after fine beam tuning, the missing $\mathrm{H}^{-}$fraction was thus well reduced to a usual lower level. However, a significant increase of the $\mathrm{H}^{-}$at the end (red) was due to a rapid foil degradation because of high-intensity operation. There was almost no $\mathrm{H}^{-}$missing the foil vertically, but peaked at the center position (C), meaning that the unstripped $\mathrm{H}^{-}$missed the foil at the injection beam hitting position due to a pinhole outbreak and also slightly from the right edge $(\mathrm{R})$ due to continuous foil deformation and curling (see Fig. 13). However, it can be noticed from the foil photographs that the foil deformation and the curling before and after $1 \mathrm{MW}$ operation did not drastically changed. The injection $\mathrm{H}^{-}$beam profile and the position on the foil were also well tuned as required. As a result, the missing $\mathrm{H}^{-}$in this case from any foil edges due to a wider beam profile (as was in the middle period) or beam position change were thus significantly smaller than those missed from the injection beam hitting position (C) due to pinhole outbreak.

We have also regularly measured the foil degradation at a position far from the injection and circulating beam hitting position to confirm that no foil degradation occurs without any beam irradiation on the foil.

Figure 15 (top) shows the injection beam positioning on the foil, which was set at $59 \mathrm{~mm}$ far from the foil edge as compared to the usual $9 \mathrm{~mm}$ during operation. The injection beam orbit was kept unchanged as in the usual operation, but the foil position was further moved $50 \mathrm{~mm}$. The waste beam orbit to the IDUMP was also thus kept the same. The partially stripped $\mathrm{H}^{0}$ and the unstripped $\mathrm{H}^{-}$ fractions were obtained by the detail measurements in the single-pass extraction mode and the injection beam dump modes. The measurement results are shown in the bottom in Fig. 15. Unlike the foil degradation shown in Fig. 12, the $\mathrm{H}^{0}$ fraction measured by both MWPM and the CT were obtained to be almost no change over the whole period as shown by the gray and light-blue solid circles, respectively. The corresponding effective foil thicknesses estimated from the MWPM and CT measurements were also almost no

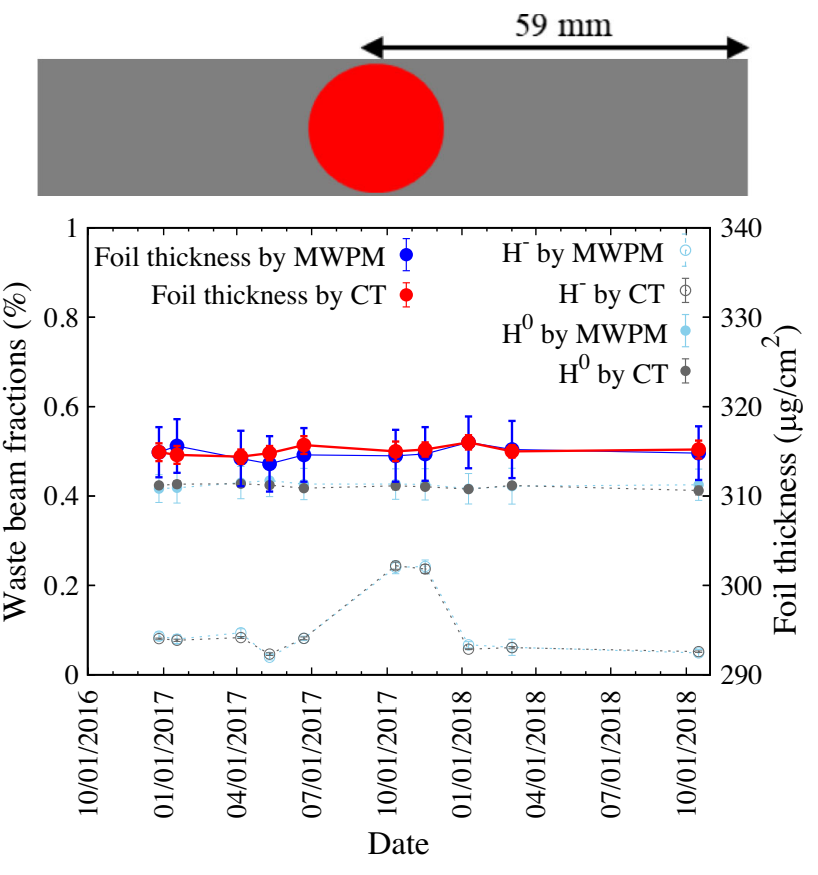

FIG. 15. Measurement of the foil degradation at $59 \mathrm{~mm}$ far from the foil edge, where ideally no particles hit the foil in usual operation. Unlike the measured foil degradations due to highintensity beam irradiation at $9 \mathrm{~mm}$ far from the foil edge (Fig. 12), there occurred no foil degradation at a position where no beam irradiation on the foil usually took place.

change as shown by the blue and red circles, respectively. The unstripped $\mathrm{H}^{-}$missing the foil vertically at the middle period was consistent with the measurements at the usual position (see Fig. 12), as those were due to a wider vertical profile of the injection $\mathrm{H}^{-}$beam. Otherwise, there was not any significant missing $\mathrm{H}^{-}$in the later period until the end and also thus indicates no formation of any pinholes at a position ideally with no beam irradiation on the foil.

The present measurement results show that a rapid foil degradation, especially at high-intensity operation, occurred due to both foil thinning and pinhole outbreak. Here we briefly discuss the considerable underlying mechanisms of the stripper foil degradation caused by the highintensity beam irradiation during CEI as obtained for the present $\mathrm{HBC}$ foil. In a CEI process, the injection $\mathrm{H}^{-}$and a greater part of the circulating protons pass through the thin foil, a thickness of about $1 \mu \mathrm{m}$. At that time, the irradiating high-energy particles induce various effects on the foil such as atomic collision, thermal effects, chemical reaction, and nuclear transmutation. Therefore, a stripper foil undergoes a various progression of physical damage (such as foil deformation, effective thickness change, and pinhole outbreak) before its breaking or complete failure. The foil thickness in the beginning was rapidly decreased due to the knockout of weakly bonding atoms in the foil because of atomic collision between the stripper foil and the high-energy beam-induced movement of atoms in the foil. 
The foil thinning rate and its continuation are thus highly related to the amount of deposited weakly bonding atoms associated mainly with foil production conditions and the underlying process. However, this rapid thinning was mitigated quickly, and, next, an amorphous-to-polycrystal transition process was dominant for the foil degradation. The HBC foil has an amorphous carbon structure, and it also has a smaller density of $1.1 \mathrm{~g} / \mathrm{cm}^{3}$ [11]. In the HBC foil, the material was changed from amorphous carbon to a polycrystalline structure graphite due to the beam irradiation as obtained from the microstructural observation by using a transmission electron microscope [11]. Earlier research of the graphite subjected to irradiation in nuclear reactors showed that the interstitial atoms knocked on by the neutrons form a pair with each other, furthermore, growing into the interstitial dislocation loop [22]. The crystallization caused a density increase and the volumetric contraction at the irradiation area by the injection beam. The volumetric contraction generated a tensile stress in the foil, and the peripheral parts were attracted to the irradiated area. As a result, the effective foil thickness was increased for a period, and the foil was macroscopically deformed, but the increment of the foil thickness was stopped through moderately changing the structure in the foil. Next, the foil thickness gradually decreased due to pyrolysis gasification. The thermal effects due to the ionization and electronic excitation not only accelerate the foil deformation and the pinhole outbreak but also play an important role of foil thinning. Recently, there has been significant progress on the foil temperature measurement at the Spallation Neutron Source, where a foil peak temperature at $1.3 \mathrm{MW}$ beam power was reported to be $1628 \mathrm{~K}$ [23]. It is at J-PARC for $1 \mathrm{MW}$ beam power estimated to be nearly $1300 \mathrm{~K}$, which is well below the carbon sublimation at around $2100 \mathrm{~K}$ at a pressure of $10^{-5} \mathrm{~Pa}$ [24]. Meanwhile, at $500 \mathrm{~kW}$ operation, the thermal radiation in visible light from the radiation spot on the stripper foil was hardly observed, which suggests that the foil temperature was further lower and below $1000 \mathrm{~K}$. Thus, the carbons in the foil were not taken off due to sublimation. However, pyrolysis gasification by the chemical reaction process can occur at a lower temperature than its sublimation point. The composition analysis by using Rutherford backscattering spectrometry and elastic recoil detection showed that the HBC foil contains many hydrogen and oxygen impurities inside $[18,25]$. These impurities are not water absorbing on the foil but form hydrocarbon groups of hydroxyl to terminate the dangling bond of the amorphous carbon clusters. The impurity atoms bonded to the carbon are decomposed and changed into carbon monoxide, carbon dioxide, and various hydrocarbon molecules at 700-1100 K. At highintensity operation, the foil heated up to an elevated temperature by beam irradiation, and the carbon-based gasses were then released from the foil. This gasification process by vacuum pyrolysis is a primary cause of foil thinning, and reduction of the effective foil thickness occurred and slowly continued for a long term.

During 2 yr user operation, the foil temperature did not rise to the sublimation point; therefore, drastic foil thinning and foil flaking off did not occur. However, radiation damage due to the displacement of atoms was continually accumulated, and pinholes were gradually generated, as well as foil curving was observed. The amorphous-topolycrystal transition is also another principle reason for pinhole outbreaks in the foil. For example, multivacancies form into the agglomerates and grow into the void, and finally huge voids make pinholes in the foil. The other one is that a tiny crack is generated at the boundaries of nanocrystal structures and grows into the crevices during the beam irradiation. The pinhole is made by the huge crevices reaching the foil surface. If the foil would have been further used for user operation, an excessive pinhole outbreak might occur, finally making a huge hole at the injection beam irradiated area. Once pinholes outbreak, the missing $\mathrm{H}^{-}$soon dominates over the $\mathrm{H}^{0}$ as was the case for the present foil at $1 \mathrm{MW}$ beam power operation. Even though the foil itself did not break, but due to such a rapid and severe foil degradation, the foil reached its end of usefulness because of excessive waste beams at the IDUMP, and it might be a foil breaking signal [11]. The foil was then replaced with a new one for the next operation. The present measurement and online monitoring for the details of stripper foil degradations, such as foil thinning, and information on the pinhole outbreak made it possible to keep the foil in service for a record of nearly $2 \mathrm{yr}$ and also successfully determine a realistic foil lifetime by ensuring proper uses with avoiding any failures during operation.

\section{SUMMARY}

The multiturn charge-exchange injection of $\mathrm{H}^{-}$by using a solid stripper foil is an established method utilized for achieving a high-intensity proton beam in almost all accelerators worldwide. However, a short lifetime and foil failures during beam operation are two serious issues not only in existing accelerators with a beam power of around $1 \mathrm{MW}$, but also for considering next-generation multimegawatt proton accelerators. Irrespective of the beam intensity, a stripper foil is usually frequently replaced to avoid any failure during beam operation. The realistic lifetime of the foil is then unknown, where frequent replacement of the foil magazine involves unhealthy radiation exposures to the workers. To ensure proper uses of a stripper foil by successfully determining its realistic end of usefulness and also to achieve a longer lifetime, we have established precise methods and also implemented an online monitoring system for measuring details of foil degradation, such as foil thinning and pinhole outbreak caused by high-intensity beam irradiation during operation at the $3-\mathrm{GeV}$ RCS of J-PARC. This is because a foil 
undergoes various degradations due to instantaneous and accumulated beam irradiation and results in foil failure. The realistic lifetime of the foil should be studied during beam operation in a realistic condition. We used two independent beam diagnostic devices and precisely measured quantitative foil thinning as well as pinhole outbreak information. We have not only achieved a record of nearly $2 \mathrm{yr}$ of operation with a single foil but also successfully determined its end of life without any breaking. The present online monitoring of the stripper foil degradation as well as the detailed measurement of the progression of foil degradation during beam operation is the first time ever it has been done anywhere.

The present research also gives strong feedback to the R\&D of stronger stripper foil production at J-PARC [26]. Many parameters in the foil production, such as the ratio of boron and carbon in the HBC foil, arc discharge voltage and discharge time to change the lattice structure, and balance between large and small grains in the foil as well as annealing procedures of the produced foil are systematically varied. The present system is used to measure foil degradation in detail for different types of foil to obtain better parameters and the process to employ for superior foil production. Through this way, a new generation of HBC foil is being produced to withstand less degradation at $1 \mathrm{MW}$ beam power and also for near future $1.5 \mathrm{MW}$ beam power operation in the RCS. While a short lifetime of the stripper foil including foil failure during beam operation is considered as a serious issue not only for the present proton accelerators with around $1 \mathrm{MW}$ beam power but also for designing the next-generation multimegawatt accelerators, the present work successfully demonstrates that one can ensure proper uses of a foil by precisely measuring a detail of foil degradation not only to determine a realistic end of life but also for achieving a longer foil lifetime without any failure. The measurement systems are very simple and ordinary, while the CT is a completely nondestructive device and, thus, easily applicable in any accelerators not only for the present particular purpose but also for any high-precision measurements.

\section{ACKNOWLEDGMENTS}

The authors highly acknowledge Dr. I. Sugai of KEK for his tireless effort for producing stronger stripper foils. We thank our entire J-PARC colleagues for continuous supports and cooperation on the present work.

[1] High-Intensity Proton Accelerator Project Team, Accelerator technical design report for J-PARC, JAERI-TECH Report No. 2003-044 and KEK Report No. 2002-13.

[2] J. Wei et al., Low-loss design for the high-intensity accumulator ring of the Spallation Neutron Source, Phys. Rev. Accel. Beams 3, 080101 (2000).
[3] H. V. Cavanagh and B. Jones, Operation with carbon stripping foils at ISIS, in Proceedings of the 2017 International Particle Accelerator Conference, IPAC'17, Copenhagen, Denmark (JACoW Publishing, Geneva, Switzerland, 2017), pp. 771-773, http://accelconf.web .cern.ch/ipac2017/papers/mopik103.pdf.

[4] C. Bracco et al., Commissioning of the stripping foil units for the upgrade of the PSB $\mathrm{H}^{-}$injection system, in Proceedings of the 2017 International Particle Accelerator Conference, IPAC'17, Copenhagen, Denmark (JACoW Publishing, Geneva, Switzerland, 2017)), MOPIK041, pp. 595-598, http://accelconf.web.cern.ch/ipac2017/papers/mopik041.pdf.

[5] M. A. Plum et al., Stripper foil failure modes and cures at the Oak Ridge Spallation Neutron Source, Phys. Rev. Accel. Beams 14, 030102 (2011).

[6] B. Jones and H. V. Cavanagh, Progress with carbon stripping foils at ISIS, in Proceedings of the 2018 International Particle Accelerator Conference, IPAC'18, Vancouver, Canada (JACoW Publishing, Geneva, Switzerland, 2018), TUPAL055, pp. 1136-1139, http:// accelconf.web.cern.ch/ipac2018/papers/tupal055.pdf.

[7] T. Spickermann, M. J. Borden, R. J. Macek, R. W. Shaw, C. S. Feigerle, and I. Sugai, Comparison of carbon and corrugated diamond stripper foils under operational conditions at the Los Alamos PSR, Nucl. Instrum. Methods Phys. Res., Sect. A 590, 25 (2008).

[8] M. Kinsho, Status and future upgrade of J-PARC accelerators, in Proceedings of the 2016 International Particle Accelerator Conference, IPAC'16, Busan, Korea (JACoW Publishing, Geneva, Switzerland, 2016), TUXA01, pp. 999-1003, http://accelconf.web.cern.ch/ipac2016/ papers/tuxa01.pdf.

[9] M. A. Plum et al., SNS proton power upgrade status, in Proceedings of the 2018 International Particle Accelerator Conference, IPAC'18, Vancouver, Canada (JACoW Publishing, Geneva, Switzerland, 2018), TUPAL049, pp. 1120-1122, http://accelconf.web.cern.ch/ipac2018/ papers/tupal049.pdf.

[10] D.A Adams et al., Studies for major ISIS upgrades via conventional RCS and accumulator ring designs, in Proceedings of the 2018 International Particle Accelerator Conference, IPAC'18, Vancouver, Canada (JACoW Publishing, Geneva, Switzerland, 2018), TUPAL058, pp. 1148-1150, http://accelconf.web.cern.ch/ipac2018/ papers/tupal058.pdf.

[11] I. Sugai, A. Takagi, Y. Takeda, Y. Irie, M. Oyaizu, and H. Kawakami, Performance characteristics of HBC stripper foils irradiated by $650 \mathrm{keV} \mathrm{H}^{-}$and high intensity DC ion beams, Nucl. Instrum. Methods Phys. Res., Sect. B 328, 70 (2014).

[12] S. G. Lebedev and A.S. Lebedev, Calculation of the lifetimes of thin stripper targets under bombardment of intense pulsed ions, Phys. Rev. Accel. Beams 11, 020401 (2008).

[13] K. Yamamoto and P. K. Saha, Recent status of J-PARC rapid cycling synchrotron, in Proceedings of the 2018 International Particle Accelerator Conference, IPAC'18, Vancouver, Canada (JACoW Publishing, Geneva, Switzerland, 2018), pp. 1045-1147, http://accelconf.web .cern.ch/ipac2018/papers/tupal020.pdf. 
[14] P. K. Saha, S. Hatakeyama, K. Yamamoto, M. Yoshimoto, H. Harada, H. Hotchi, Y. Shobuda, M. Kinsho, K. Satou, and Y. Irie, State of the art online monitoring system for the waste beam in the rapid cycling synchrotron of the Japan Proton Accelerator Research Complex, Phys. Rev. Accel. Beams 14, 072801 (2011).

[15] P. K. Saha, M. Yoshimoto, Y. Yamazaki, H. Hotchi, H. Harada, K. Okabe, M. Kinsho, and Y. Irie, Measurement of $181 \mathrm{MeV} \mathrm{H}^{-}$ions stripping cross-sections by carbon stripper foil, Nucl. Instrum. Methods Phys. Res., Sect. A 776, 87 (2015).

[16] P. K. Saha, Y. Shobuda, H. Hotchi, N. Hayashi, T. Takayanagi, H. Harada, and Y. Irie, Direct observation of the phase space footprint of a painting injection in the rapid cycling synchrotron at the Japan Proton Accelerator Research Complex, Phys. Rev. Accel. Beams 12, 040403 (2009).

[17] H. Hotchi et al., Beam loss reduction by injection painting in the 3-GeV rapid cycling synchrotron of the Japan Proton Accelerator Research Complex, Phys. Rev. Accel. Beams 15, 040402 (2012).

[18] I. Sugai et al., Development of thick hybrid-type carbon stripper foils with high durability at $1800 \mathrm{~K}$ for RCS of J-PARC, Nucl. Instrum. Methods Phys. Res., Sect. A 561, 16 (2006).

[19] S. Hiroki et al., Multi-wire profile monitor for J-PARC $3 \mathrm{GeV}$ RCS, in Proceedings of the 11th European Particle Accelerator Conference, Genoa, 2008 (EPS-AG, Genoa, Italy, 2008), pp. 1131-1133.
[20] H. Sako et al., An application for beam profile reconstruction with multi-wire profile monitors at J-PARC $\mathrm{RCS}$, in Proceedings of the 11th European Particle Accelerator Conference, Genoa, 2008 (EPS-AG, Genoa, Italy, 2008), pp. 1272-1274.

[21] P. K. Saha for the RCS team, Experience with J-PARC RCS injection and extraction systems, in Proceedings of 42nd ICFA advanced beam dynamics workshop (HB2008), Nashville, Tennessee, 2008, pp. 275-283, http://accelconf .web.cern.ch/HB2008/papers/wgc05.pdf.

[22] B. T. Kelly et al., Graphite-the most fascinating nuclear material, Carbon 20, 3 (1982).

[23] W. Blokland et al., Injection foil temperature measurements at the SNS accelerator, in Proceedings of 61st ICFA advanced beam dynamics workshop (HB2018), Daejeon, Korea, 2018 (JACoW Publishing, Geneva, Switzerland, 2018), TUP2WE01, pp. 104-109, http://accelconf.web .cern.ch/hb2018/papers/tup2we01.pdf.

[24] Z. Jaworski, B. Zakrzewska, and P. Pianko-Oprych, On thermodynamic equilibrium of carbon deposition from gaseous C-H-O mixtures: Updating for nanotubes, Rev. Chem. Eng. 33, 217 (2017).

[25] Y. Yamazaki, M. Yoshimoto, O. Takeda, M. Kinsho, T. Taguchi, S. Yamamoto, T. Kurihara, and I. Sugai, Analysis of hybrid type boron-doped carbon stripper foils in J-PARC RCS, J. Phys. Conf. Ser. 417, 012071 (2013).

[26] Y. Yoshimoto et al., Progress status in fabrication of HBC stripper foil for 3-GeV RCS of J-PARC in Tokai site, EPJ Web Conf. 229, 01001 (2020). 